\title{
GEOGRAPHIC VARIATION IN MATERNAL INVESTMENT: ACIDITY AFFECTS EGG SIZE AND FECUNDITY IN RANA ARVALIS
}

\author{
Katja Rasanen, ${ }^{1,3}$ Fredrik Soderman, ${ }^{1}$ Anssi Laurila, ${ }^{1}$ and Juha Merila ${ }^{2}$ \\ ${ }^{1}$ Department of Population and Conservation Biology, Evolutionary Biology Centre, Uppsala University, Norbyvägen 18 D, \\ SE 75236 Uppsala, Sweden \\ ${ }^{2}$ Ecological Genetics Research Unit, Department of Biological and Environmental Sciences, P.O. Box 65, \\ FIN 00014 University of Helsinki, Finland
}

\begin{abstract}
Environmental stress mediated geographic variation in reproductive parame ters has been little studied in natural vertebrate populations outside the context of climatic variation. Based on life history theory, an increase in the degree of environmental stress experienced by a population should lead to (1) a shift in reproductive allocation from fecundity to offspring quality, (2) stronger trade offs between reproductive parameters, and (3) changes in the relationship between female phenotype and maternal investment. To test these predictions, we investigated geographic variation in maternal investment of moor frogs (Rana arvalis) in relation to breeding site acidity ( $\mathrm{pH} 48$ ). We found that mean egg size increased and clutch size and total reproductive output (TRO) decreased with increasing acidity among 19 Swedish moor frog populations. Tests for variation and co variation in maternal investment and female size and age in 233 females from a subset of four acid origin (AO) and four neutral origin (NO) populations revealed that clutch size and TRO increased with female size in both acid and neutral environments. However, in AO populations, egg size also increased with female size, and clutch size and TRO with female age, whereas in NO populations, egg size increased with female age. The strength of the egg size clutch size trade off tended to be stronger in $\mathrm{AO}$ than in NO females as expected if the former experience stronger environmental constraints. All in all, these results suggest that environmental acidification selects for investment in larger eggs at a cost to fecundity, imposes negative effects on reproductive output, and alters the relationship between female phenotype and maternal investment.
\end{abstract} off.

Key words: amphibians; egg size; environmental stress; fecundity; life history; $p H$; reproduction; trade

\section{INTRODUCTION}

Environmental stress can be a major evolutionary force and, accordingly, some of the most clear cut examples of contemporary evolution come from re sponses to anthropogenic environmental change (Hoff mann and Parsons 1997, Reznick and Ghalambor 2001). There are many examples of evolution of resistance to specific stressors (reviewed by Reznick and Ghalambor 2001) and ample evidence for strong selection on maternal investment via temperature and seasonal time constraints (Fleming and Gross 1990, Poulin 1995, Armbruster et al. 2001, Johnston and Leggett 2002). However, how other environmental stressors influence investment in offspring quality and quantity has been little explored in natural populations.

Manuscript received 31 January 2007; revised 18 December 2007; accepted 23 January 2008. Corresponding Editor: D. K. Skelly.

3 Present address: ETH Zurich, Institute of Integrative Biology (IBZ)/Eawag, Department of Aquatic Ecology, Ueberlandstrasse 133, CH 8600 Duebendorf, Switzerland. E mail: katja.rasanen@eawag.ch
According to life history theory, maternal investment can be seen as an optimization problem between the fitness of a female and the fitness of her offspring (Smith and Fretwell 1974, Roff 1992). Consequently, a repro ductive female needs to optimize her resource allocation between current and future reproduction, reproduction and growth/maintenance, as well as among individual offspring (Roff 1992, Sinervo 1999). Environmental stress may increase variation in fitness, thereby strength ening the importance of optimal allocation of resources, as well as change the adaptive optima compared to benign environments. First, because stressful environ ments are physiologically costly, a female may have to allocate more resources to maintenance at a cost to reproduction. Second, poor quality environments are expected to favor investment on offspring quality (McGinley et al. 1987, Hutchings 1991, Sinervo et al. 1992, Einum and Fleming 1999, but see Kaplan and Phillips 2006) at a cost to offspring quantity (Roff 1992, Stearns 1992, Einum and Fleming 2000). Third, reproductive parameters often strongly depend on female size and age, which in turn can be influenced by environmental stress and resource availability, variation in the direct fitness benefits of a particular 
reproductive strategy, as well as population demography (Roff 1992, Stearns 1992). Because the optimal maternal investment strategy depends both on the mothers' quality and environment and on the offspring environ ment (Parker and Begon 1986, Kisdi et al. 1998, Einum and Fleming 1999, Hendry et al. 2001), stressful environments should favor different reproductive strat egies than less stressful environments. Here, we tested if environmental acidity shifts maternal investment from offspring quantity towards offspring quality and how this variation may respond to variation in female size and age in the moor frog, Rana arvalis.

Studies on amphibians inhabiting environments that vary in acidity provide a good model system to study life history evolution in stressful environments. First, acid environments reduce survival and slow down growth and development rates of amphibians (Pierce 1985; Räsänen and Green, in press) and other organisms (e.g., Rusek and Marshall 2000), and may have demographic consequences via reductions in breeding population size (e.g., reviewed for amphibians in Räsänen and Green [in press]) and altered age structure of populations (e.g., in fish [Trippel and Harvey 1987]). Second, variation in acidity among natural environ ments exposes populations to different selective pres sures (Collier et al. 1990, Dangles et al. 2004). Selection for local adaptation in acid tolerance and life histories can be particularly strong and rapid in environments influenced by anthropogenic acidification (Pierce 1985, Räsänen et al. 2003a, 2005, Derry and Arnott 2007). Whereas geographic variation in acid tolerance has been studied to some extent, the potential impacts of acidity on adult life history traits have remained largely unexplored.

In our previous studies on $R$. arvalis, we found evidence for local adaptation via maternal effects in embryonic acid stress tolerance (viz. survival [Räsänen et al. 2003a, $b$, Merilä et al. 2004]) and positive effects of large egg size on larval fitness components (viz. development rate and metamorphic size) under acid conditions (Räsänen et al. 2005). The latter observation suggests that maternal investment in large egg size is adaptive in acid environments, and females indeed appear to invest in larger eggs in acid than in neutral habitats (Räsänen et al. 2005). However, how wide spread this pattern is and how other reproductive parameters, especially clutch size and maternal pheno type, correlate with variation in egg size is not currently known.

To test the predictions arising from life history theory, we investigated variation in egg size, clutch size and total reproductive output among $R$. arvalis popu lations varying in $\mathrm{pH}(\mathrm{pH} 48)$ of breeding sites using two data sets: clutches collected from the wild in 19 populations (clutch data) and clutches produced in the laboratory (from females caught from the wild) where variation in maternal investment parameters could be directly linked to the phenotype of the individual females (clutch by female data). We made three main predictions. First, under the assumption that large eggs are adaptive in acid (but not in neutral) environments, acid origin females should invest in larger eggs than neutral origin females. Second, under the assumptions that (1) there exists a trade off between investment in egg size and clutch size and (2) acid environments are more stressful than neutral environments, females should have smaller clutches and show a stronger trade off between egg and clutch size in acid than in neutral environments. Third, under the assumption that environmental stress may change the optimal pheno type dependent reproductive strategies as well as a female's ability to invest in reproduction, we expected acid and neutral environments to differ in the relation ships between maternal investment and female size and age. We specifically predicted that, if egg size is the target of selection in acid populations, it should increase more strongly with female size in acid than in neutral populations.

\section{Material And Methods}

$R$. arvalis is a small brown frog, with a wide distribution in northern and central Europe to the Ural Mountains in the east (Glandt 2006). It is relatively acid tolerant (e.g., Leuven et al. 1986, Andrén et al. 1988), and starts breeding in southern Sweden in early April and in northern Sweden in late May. Females lay one clutch of 3001500 eggs per year. Both sexes mature at an age of two to three years, with most breeding individuals in our populations being two to three years old and the oldest being six years old (Söderman 2006).

\section{Clutch data set}

Data on maternal investment were collected from 19 Swedish $R$. arvalis populations situated along a $1000 \mathrm{~km}$ latitudinal gradient from southern Scania $\left(55^{\circ} 30^{\prime} \mathrm{N}\right)$ to northern Västerbotten ( $63^{\circ} 43^{\prime}$ N, Fig. 1, Appendix A). Environmental variables recorded for each location were altitude, latitude, and $\mathrm{pH}$. These are clearly not the only ecological variables that may differ between popula tions, but serve as surrogates for large scale environ mental shifts related to climate, season length, and acidification. At each pond, $\mathrm{pH}$ was measured at four different locations $(10 \mathrm{~cm}$ depth and about $50 \mathrm{~cm}$ distance from the pond shore) with a Ross sure flow electrode $8165 \mathrm{BN}$ and an Orion 210A pH meter (Orion Research, Beverly, Massachusetts, USA). The average of the four measures was used in the analyses. The exact acidification history of the study sites is not known, but large parts of Sweden (especially in the southwest; Fig. 1) have been severely impacted by anthropogenic acidification resulting from "acid rain" during the first half of the 20th century (Renberg et al. 1993), and the lakes likely vary in the relative importance of anthro pogenic and natural acidity (Guhrén et al. 2007).

Clutch parameters were sampled in 463 clutches at each location (Appendix A). The clutches were sampled 


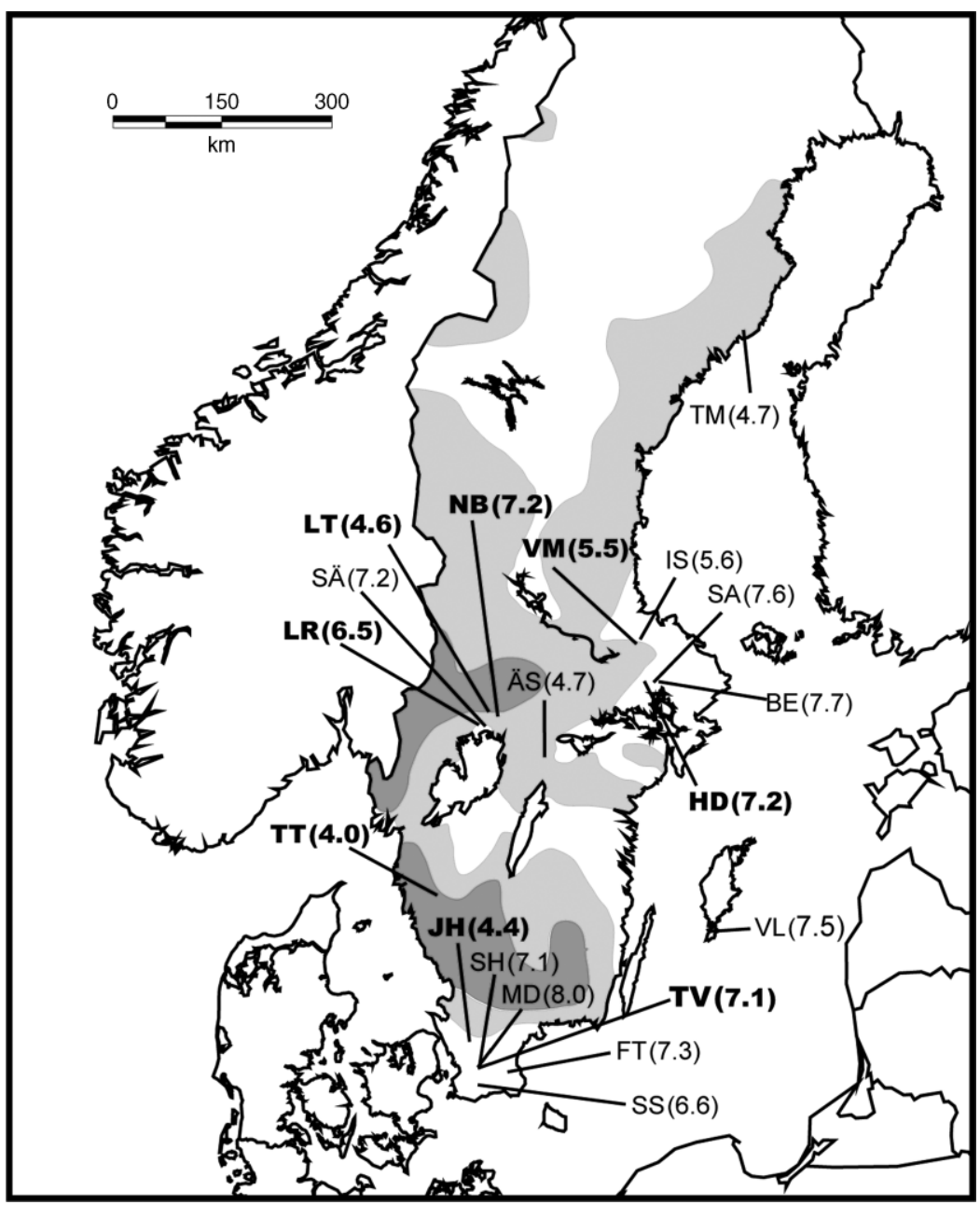

FIG. 1. Map of Sweden showing the locations of the 19 study populations of Rana arvalis with abbreviations for locality names and breeding site $\mathrm{pH}$ (in parentheses). The eight populations used in the individual level analyses are shown in boldface type (acid origin [AO] populations JH, TT, LT, and VM; neutral origin [NO] populations TV, LR, NB, and HD). Also shown is the acidification situation as in 1990 (following Swedish Environmental Protection Agency, Report 4421. There has been little change since 1990). The percentage of acidified lakes is indicated by shading: dark gray, $>50 \%$; light gray, $1050 \%$; white, $<10 \%$. See Appendix A for full description of sites.

before the eggs had reached developmental stage 12 (Gosner 1960) to ensure that egg size measurements were comparable. Clutch size was estimated by first measuring the total volume of the clutch using a $2 \mathrm{~L}$ measuring cylinder, and then measuring the volume of a subsample of a known number of eggs $(\sim 100)$ with a $0.1 \mathrm{~L}$ measuring cylinder. For the egg size measure ments, 2040 eggs per female (covered with water and illuminated from below) were photographed. A black and white negative image was then scanned with an Agfa DuoScan (at 1000 dpi; Agfa Gaevert, Mortsel, Belgium) and saved for analyses in the NIH image program (version 1.61, available online). ${ }^{4}$ Egg size was measured as the minimum and maximum diameter for each egg to the nearest $0.05 \mathrm{~mm}$, which were averaged to

\footnotetext{
${ }^{4}\langle$ http://rsb.info.nih.gov/nih image $\rangle$
}

get an estimate of egg diameter. Assuming the eggs are spherical, we then calculated egg volume. Clutch means of egg volume were used in the final analyses of egg size. Since $R$. arvalis produces one clutch/year, we calculated total reproductive output (henceforth, TRO; the product of clutch size and egg volume) for each female to get an estimate of total maternal investment during one season.

\section{Clutch by female data set}

Data on female phenotypes and clutch parameters was collected from a total of 233 female $R$. arvalis in a subset of eight populations originating from four acid ( $\mathrm{pH} \leq 5.5$, henceforth $\mathrm{AO}$ ) and four neutral $(\mathrm{pH} \geq 6.5$, henceforth NO) sites in southern and central Sweden (Fig. 1, Appendix A). These eight populations were chosen because they have been the focus of other studies and data on female phenotype hence were available 
(Räsänen et al. 2003a, 2005, Söderman et al. 2007; K. Räsänen, F. Söderman, A. Laurila, and J. Merilä, unpublished data). Females were collected from the breeding ponds at the onset of breeding over a period of three years (1999, 2000, and 2002). In each population, 1241 females were measured for egg size, clutch size, snout vent length (SVL), and age, but the amount of available data varies among traits (Appendix A). SVL of each female was measured with digital calipers to the nearest $0.1 \mathrm{~mm}$. Eggs from these females were obtained from artificial crosses (see Räsänen et al. $2003 a$ for details) and where hence subject to similar conditions. Number of eggs for each female was counted manually to get clutch size, and egg size on newly fertilized eggs was measured from photographic images as described previously.

Age of the females was determined using skeletochro nological methodology (Castanet et al. 1977). In amphibian bone, a yearly growth layer consists of a band of bone tissue bordered by a dark line of arrested growth (LAG). Sections of the second phalange of the right hind leg were prepared using standard methods (e.g., Castanet et al. 1977, 1993, Hemelaar 1985) and the number of rings (corresponding to female age) was determined from a section photographed with a digital camera fitted to a stereomicroscope. The resting lines were marked in Adobe Photoshop (version 6.0; Adobe Systems, San Jose, California, USA) and the perimeter measured for all rings using the NIH image software (see footnote 4). Directly after metamorphosis, the new build up of endosteal bone leads to resorbtion of the periosteal bone with the consequence that the innermost LAGs can completely disappear. To get a reliable estimate of age, individuals of known age were hence used as a reference and the number of missing LAGs estimated using methods described in Hemelaar (1985).

\section{Statistical analyses}

Clutch parameters (egg size, clutch size, and TRO) were analyzed with general linear mixed models. In the analyses on the clutch data set, population was treated as a random factor, and $\mathrm{pH}$, altitude $(\mathrm{m})$, and latitude (meters from the equator) as covariates. Egg size and clutch size were used as covariates of one another when testing for a trade off between them. All covariates were centered before analyses. The analyses were started with a full model, with all possible interactions, and then removing nonsignificant interactions $(P>0.1)$ starting with the least significant. Only the results from the final models are presented.

In the clutch by female analyses, clutch parameters and female phenotype were analysed with nested mixed model ANCOVAs. Population (nested within origin) was treated as a random effect, origin (AO and NO) as a fixed effect, and all other variables as covariates. Because of the strong effect that climate and season length can have on ectotherm life histories, all ANOVAs were initially run with latitude as a covariate. The models were run in three main steps. To test whether the results from this data set parallel those of the clutch data set, the first set of models included population, origin, and latitude only. To then test for the effects of female phenotype on maternal investment, female age and size (covariates) as well as their interactions with origin were included in the second set of models. To also test for the egg size clutch size trade off, the third set of models was run including egg size or clutch size, respectively, as well as female phenotype and their interactions with origin. Models were chosen by testing equalities of slope's (i.e., significant interaction terms) and their difference from zero (Littell et al. 2006), and the final analyses were run omitting nonsignificant $(P>0.1)$ interactions. The residuals from the models were tested for normality with a Kolmogorov Smirnov test prior to final analyses. We used log transformed values in all analyses, but for ease of interpretation, original data and/or back transformed values for least squares means and slopes (b) are presented (note that standard errors are back trans formed from $\log$ transformed data, resulting in asym metrical standard errors). All analyses were run using REML estimation of random effects in Proc MIXED in SAS (version SAS 9.1; Littell et al. 2006), and applying Satterthwaite procedure, which approximates the de grees of freedom and is recommended for mixed models with complex covariance structures (for details, see Littell et al. [2006]).

\section{RESUlts}

Clutch data

Mean egg size increased, whereas clutch size and TRO decreased with decreasing $\mathrm{pH}$ across the 19 populations (Fig. 2A, B, Table 1). Egg size decreased and clutch size increased also with increasing altitude, whereas TRO decreased with increasing latitude (Table 1).

When clutch size was included in the model for egg size, it was negatively associated with egg size $(b \pm$ upper/lower SE, $0.285 \pm 0.085 / 0.096 ; F_{1,449}=7.18$, $P=0.008$, but this effect depended on $\mathrm{pH}(\mathrm{pH} \times$ clutch size, $\left.F_{1,450}=7.41, P=0.007\right)$. Similarly, when egg size was included in the model for clutch size, it was negatively associated with clutch size $(b=0.695 \pm$ $\left.0.123 / 0.205 ; F_{1,422}=5.34, P=0.021\right)$ and this effect depended on $\mathrm{pH}\left(\mathrm{pH} \times\right.$ egg size, $F_{1,424}=5.26, P=$ 0.022). These effects arose because low $\mathrm{pH}$ populations were characterized by large and few eggs whereas the opposite was true for neutral populations, indicating a population level trade off between fecundity and egg size (Fig. 2A).

\section{Clutch by female data}

Both female size and age increased with increasing latitude (size, $b=0.028 \pm 0.009 / 0.009 ; P=0.029$; age, $b=0.050 \pm 0.011 / 0.012, P=0.023$, but neither female size nor age differed significantly among $\mathrm{AO}$ and $\mathrm{NO}$ females (size, $F_{1,5.05}=0.92$; age, $F_{1,2.77}=3.13$; both, $P>$ 0.18; Appendix A) or among populations within origins 

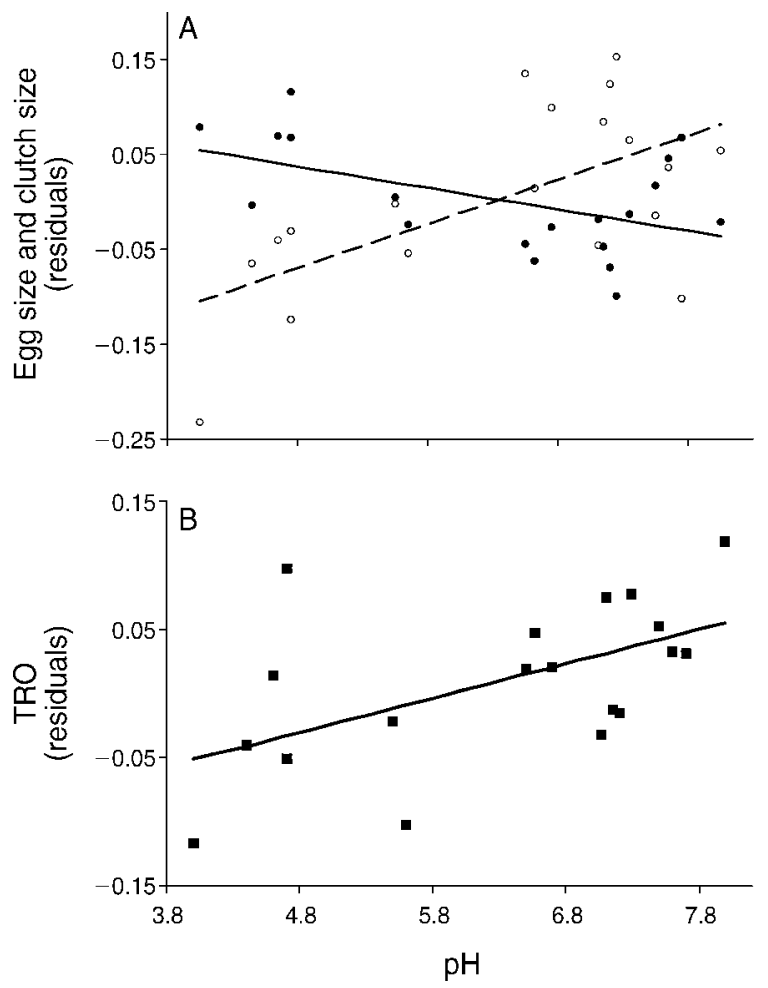

FIG. 2. Relationship between breeding pond $\mathrm{pH}$ and (A) egg size (solid circles) and clutch size (open circles) and (B) total reproductive output (TRO) in $19 R$. arvalis populations. Each dot represents the residual mean value for a given population corrected for the effect of altitude (in A) and latitude (in B). For test statistics, see Table 1.
$(P>0.07)$. While female age had a strong positive effect on female size $(b=0.171 \pm 0.033 / 0.034, P<0.001)$, the results on size remained qualitatively unchanged when age was included in the model (not shown).

When only population, origin, and latitude effects were included in the models, egg size did not differ significantly between $\mathrm{AO}$ and $\mathrm{NO}$ females $\left(F_{1,5.1}=2.13\right.$, $P=0.203)$. AO females produced marginally fewer eggs (AO, LS means \pm lower/upper S.E. 836.15 \pm $79.67 / 88.04 ; \mathrm{NO}, 1199 \pm 114.19 / 126.20 ; F_{1,5}=6.17$, $P=0.056$; Fig. 3A), but did not have a significantly lower TRO than NO females $\left(F_{1,4.83}=3.45 ; P=0.125\right.$, Fig. 3B). Population or latitude did not have significant effects on any of the clutch parameters (all $P>0.07$ ).

When female phenotypic traits, and their interactions with origin, were included in the models as covariates, AO females had slightly larger eggs $(2.834 \pm 0.186 / 0.196$ $\left.\mathrm{mm}^{3}\right)$ than NO females $\left(2.508 \pm 0.173 / 0.182 \mathrm{~mm}^{3}\right)$, but this difference was not significant $(P=0.084$; Table 2$)$. Egg size increased with both female size and age (Table 2). The positive effect of female size was significantly different from zero only for the AO females, whereas the positive effect of female age was signifi cantly different from zero only for the NO females (Appendix B, Fig. 4A, B). The slopes were significantly different between $\mathrm{AO}$ and $\mathrm{NO}$ females only for size (origin $\times$ size, $P=0.046$; origin $\times$ age, $P=0.084$ ).

Clutch size increased strongly with female size $(b=$ $10.257 \pm 1.985 / 2.410$; Table 2), and this effect was independent of origin (Table 2). However, as indicated by a significant origin $\times$ age interaction $(P=0.006)$, clutch size increased also with female age in $\mathrm{AO}$ but not in NO females (Fig. 4, Table 2, Appendix B).

TABLE 1. Analyses of covariance on egg size, clutch size, and total reproductive output (TRO) for 19 Rana arvalis populations differing in breeding pond acidity.

\begin{tabular}{|c|c|c|c|c|c|c|c|}
\hline \multirow{2}{*}{$\begin{array}{l}\text { Source of } \\
\text { variation }\end{array}$} & \multicolumn{3}{|c|}{ Random } & \multicolumn{4}{|c|}{ Fixed } \\
\hline & Var & $\mathrm{SE}$ & $Z$ & $\mathrm{df}$ & $b$ & SE & $F$ \\
\hline \multicolumn{8}{|l|}{ Egg size } \\
\hline Population & 0.19 & 0.08 & $2.32 *$ & & & & \\
\hline Residual & 0.41 & 0.03 & $14.80^{* * *}$ & & & & \\
\hline $\mathrm{pH}$ & & & & $1,13.9$ & 0.030 & $0.010,0.010$ & $8.50 *$ \\
\hline Latitude & & & & $1,14.9$ & 1.418 & $1.202,2.389$ & 1.65 \\
\hline Altitude & & & & 1,13 & 0.081 & $0.028,0.029$ & $7.33^{*}$ \\
\hline \multicolumn{8}{|l|}{ Clutch size } \\
\hline Population & 0.45 & 0.20 & $2.26^{* *}$ & & & & \\
\hline Residual & 1.69 & 0.10 & $16.86^{* * *}$ & & & & \\
\hline $\mathrm{pH}$ & & & & 1,14 & 0.070 & $0.017,0.017$ & $18.09 * * *$ \\
\hline Latitude & & & & $1,14.3$ & 2.963 & $2.605,7.602$ & 1.29 \\
\hline Altitude & & & & $1,12.9$ & 0.107 & $0.053,0.056$ & $4.35^{*}$ \\
\hline \multicolumn{8}{|l|}{ TRO } \\
\hline Population & 0.95 & 0.83 & 1.15 & & & & \\
\hline Residual & 26.14 & 1.77 & $14.81^{* * *}$ & & & & \\
\hline $\mathrm{pH}$ & & & & $1,13.7$ & 0.025 & $0.011,0.011$ & $5.67 *$ \\
\hline Latitude & & & & $1,15.8$ & 11.769 & $6.833,14.699$ & $11.06^{* *}$ \\
\hline Altitude & & & & $1,9.44$ & 0.009 & $0.029,0.030$ & 0.09 \\
\hline
\end{tabular}

Note: Back transformed slopes $(b)$ are given with their (lower/upper) SE.

* $P<0.05$; ** $P<0.01$; *** $P<0.001$. 

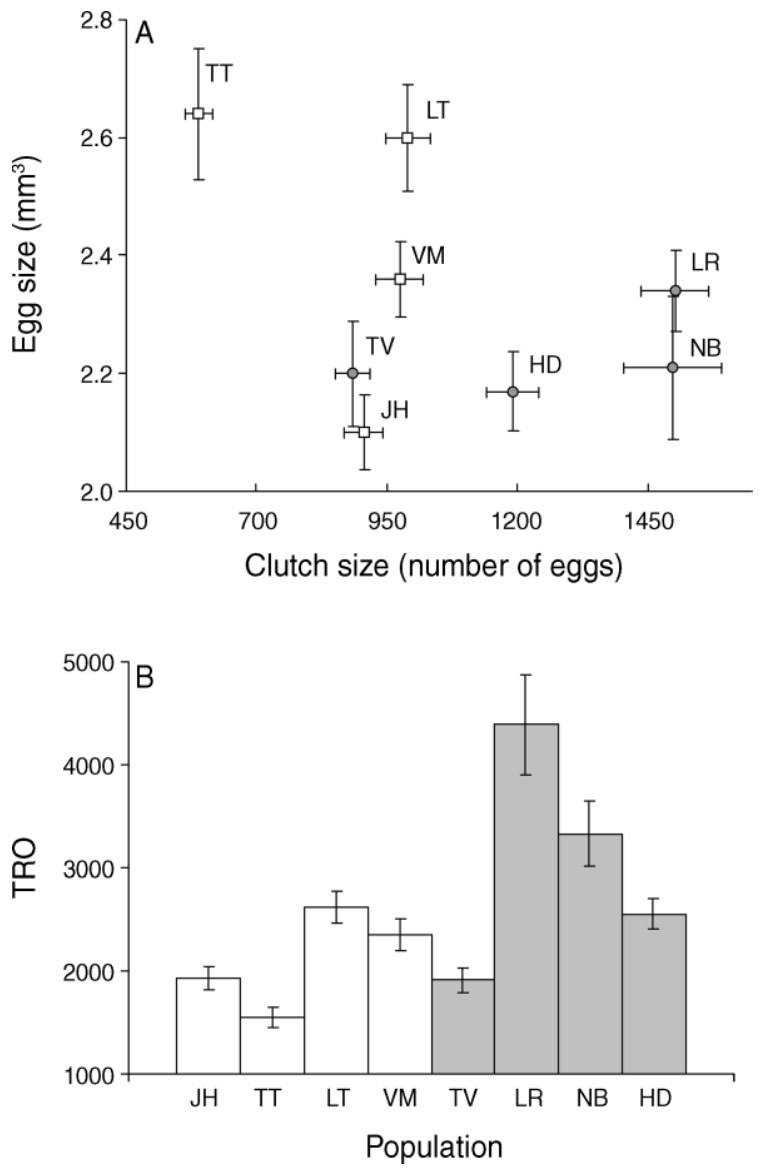

FIG. 3. (A) Egg size and clutch size and (B) TRO in four acid (open squares and bars) and four neutral (solid circles and bars) origin populations of $R$. arvalis. Codes for population origin are as in Table 1. Values are means \pm SE.

TRO increased with both female size $(b=10.325 \pm$ $3.002 / 4.085, P<0.001)$ and age $(b=0.390 \pm$ $0.132 / 0.146, P=0.003$; Table 2 ), suggesting a relatively higher investment in reproduction later in life. After controlling for the effects of female phenotype, $\mathrm{AO}$ females had a lower TRO (LS means \pm lower/upper S.E.: $2452.84 \pm 177.23 / 232.48)$ than NO females $(2903.45 \pm 215.25 / 232.48$; Table 2). TRO increased marginally more strongly with female size in AO than NO females (origin $\times$ female size, $P=0.056$; Fig. 4; Table 2; Appendix B).

In accordance with the clutch data set, there was an overall significant negative relationship between egg and clutch size $(b=0.097 \pm 0.056 / 0.060$; Appendix C), indicative of an egg size clutch size trade off. After controlling for variation in clutch size, AO females had significantly larger eggs (LS means \pm lower/upper S.E.: $\left.2.717 \mathrm{~mm}^{3} \pm 0.149 / 0.156\right)$ than NO females $(2.561$ $\mathrm{mm}^{3} \pm 0.150 / 0.156$, Appendix C). The slopes of clutch on egg size did not differ significantly between $\mathrm{AO}$ and NO females (origin $\times$ clutch size: $P=0.094$ ), although the negative relationship between egg and clutch size was significantly different from zero only for AO females (Fig. 4, Appendix B, C). Also when egg size was included as a covariate in the model on clutch size, the strong negative effect of egg size on clutch size was evident overall $(b=0.342 \pm 0.080 / 0.091, P=0.002$, Appendix C) and within AO females (Fig. 4, Appendix C).

\section{Discussion}

Our results lend support to the hypothesis that maternal investment strategies differ between physio logically stressful (acid) and more benign (neutral) environments. The clutch data on $19 R$. arvalis populations showed that females invest in larger but fewer eggs, and have a lower reproductive output (TRO) in acid than in neutral environments (Fig. 2). The clutch by female data further suggested that the strength of the egg size clutch size trade off, as well as the relationship between female phenotype (size and age) and maternal investment, differ between acid and neutral environ ments (Fig. 4). We next consider the implications of these results for the understanding of how acidity can influence geographic variation in life histories.

\section{Maternal investment variation among acid and neutral environments}

The finding that egg size increased with increasing breeding site acidity supports the hypothesis that large egg size is selected for in acid environments (Räsänen et al. 2005). This likely is a result from large egg/hatchling size having beneficial effects on larval and metamorphic performance (Räsänen et al. 2005) and, hence, presumably also on lifetime fitness (e.g., Smith 1987, Berven 1990, Scott 1994). Likely underlying mechanisms include variation in the amount of resourc es and the surface to volume ratio of the eggs. In particular, a larger amount of yolk and nutrients in larger eggs (Komoroski et al. 1998) may allow offspring to overcome the increased energetic requirements posed by physiological stress or limited resources in acid habitats. A smaller surface to volume ratio of larger offspring, on the other hand, may reduce loss of sodium, which is the major physiological impact of acid stress in larvae (reviewed in Räsänen and Green, in press).

Second, the finding that clutch size decreases with increasing acidity suggests that investment in larger eggs and/or maintenance comes at a cost to fecundity, in line with the basic tenets of life history theory (cf. Roff 1992, Stearns 1992). Maternal feeding conditions often influ ence maternal investment (Gliwicz and Guisande 1992, Ford and Seigel 1994, Girish and Saidapur 2000) and it is possible that the observed among population varia tion in clutch parameters is a consequence of acid environments being physiologically stressful and/or resource limited during clutch production. Acidity is known to cause physiological stress also during terres trial life stages (reviewed in Räsänen and Green, in press) but, at least to our knowledge, no study has 
TABLE 2. Analyses of covariance of egg size, clutch size, and total reproductive output (TRO) in R. arvalis females from four acid and four neutral populations in a model including female phenotype.

\begin{tabular}{|c|c|c|c|c|c|}
\hline \multirow{2}{*}{$\begin{array}{l}\text { Source of } \\
\text { variation }\end{array}$} & \multicolumn{3}{|c|}{ Random } & \multicolumn{2}{|c|}{ Fixed } \\
\hline & Var & $\mathrm{SE}$ & $Z$ & $\mathrm{df}$ & $F$ \\
\hline \multicolumn{6}{|l|}{ Egg size } \\
\hline Population & 0.39 & 0.26 & $1.44 \dagger$ & & \\
\hline Residual & 0.42 & 0.05 & $8.52 * * *$ & & \\
\hline Origin & & & & 1,150 & $3.01 \dagger$ \\
\hline Latitude & & & & $1,5.38$ & 0.00 \\
\hline Female age & & & & 1,147 & $11.09 * *$ \\
\hline Female size & & & & 1,149 & $8.59^{* *}$ \\
\hline Origin $\times$ female age & & & & 1,148 & $3.16 \dagger$ \\
\hline Origin $\times$ female size & & & & 1,149 & $4.07^{*}$ \\
\hline \multicolumn{6}{|l|}{ Clutch size } \\
\hline Population & 1.77 & 1.20 & $1.47 \dagger$ & & \\
\hline Residual & 2.74 & 0.30 & $9.03 * * *$ & & \\
\hline Origin & & & & $1,90.5$ & $14.04 * * *$ \\
\hline Latitude & & & & $1,5.3$ & 0.27 \\
\hline Female age & & & & 1,165 & 0.59 \\
\hline Female size & & & & 1,167 & $156.00^{* * *}$ \\
\hline Origin $\times$ female age & & & & 1,168 & $7.82 * *$ \\
\hline Origin $\times$ female size & & & & 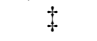 & $\ddagger$ \\
\hline \multicolumn{6}{|l|}{ TRO } \\
\hline Population & 2.05 & 1.43 & $1.44 \uparrow$ & & \\
\hline Residual & 3.62 & 0.43 & $8.47 * * *$ & & \\
\hline Origin & & & & 1,145 & $4.07 *$ \\
\hline Latitude & & & & $1,5.56$ & 0.42 \\
\hline Female age & & & & 1,146 & $10.62 * *$ \\
\hline Female size & & & & 1,148 & $146.61 * * *$ \\
\hline Origin $\times$ female age & & & & \pm & $\ddagger$ \\
\hline Origin $\times$ female size & & & & 1,146 & $3.71 \dagger$ \\
\hline
\end{tabular}

$\dagger P<0.10 ; * P<0.05 ; * * P<0.01 ; * * * P<0.001$.

\$ Nonsignificant interactions that were excluded from these final models.
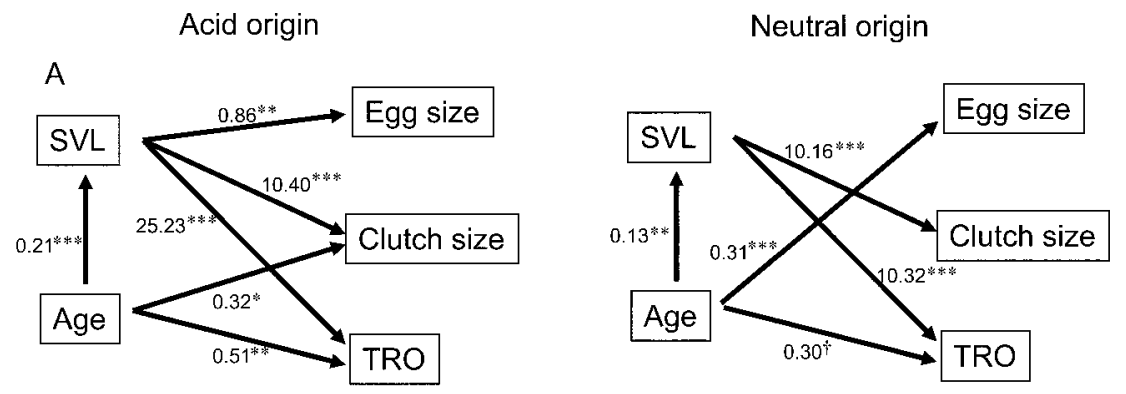

B


FIG. 4. Regression coefficients (slope, $b$ ) for (A) effects of female phenotype (age and SVL) on maternal investment parameters (egg size, clutch size, and total reproductive output [TRO]) and (B) the relationship between clutch size and egg size in acid origin and neutral origin populations. Dashed arrows indicate negative relationships. For clarity, only statistically significant effects are illustrated. The significance of $b$ is indicated next to the slope estimate: $\dagger P<0.06$; $* P<0.05 ; * * P<0.01 ; * * * P<0.001$. The tests for slope differences between origins can be found in Table 2 and Appendix C. 
directly investigated whether resource availability is related to acidity during the terrestrial stages in amphibians.

Third, the significant negative relationship between clutch and egg size in AO (but not in NO) females in the clutch by female data, reinforces the suggestion that genetic and phenotypic trade offs can be stronger in stressful environments (e.g., Tuomi 1990, Reznick et al. 2000, Czesak and Fox 2003). Although the slopes did not differ significantly $(P<0.1)$ between AO and NO females, the finding provides rare empirical evidence for differences in the strength of such trade offs among wild populations (see also Olsen and Vøllestad 2003). The particular mechanisms mediating such trade offs could be due to, for instance, mechanical limitations (e.g., Kaplan and Salthe 1979, Sinervo and Licht 1991, Olsson and Shine 1997) or because the relative importance of variation in resource acquisition and allocation dictates the relationship among life history traits (Van Noord wijk and de Jong 1986, Reznick et al. 2000). In our case, it seems likely that acidity prohibits simultaneous investment in reproduction and in mechanisms to counteract physiological acid stress, but more detailed investigations are needed to address this possibility.

In conclusion for this part, the larger but fewer eggs in acid environments is most plausibly due to natural selection favoring large egg size at a cost to fecundity. However, acidity also appears to have a direct negative effect on fecundity, as suggested by the fact that the effects were stronger and more consistent on clutch size and TRO than on egg size. The genetic basis for among population variation in clutch size and TRO needs to be confirmed, but we suggest that the lower TRO in acid environments reflects a cost of reproduction arising from physiological stress.

\section{Effects of female phenotype on maternal investment}

Life history theory predicts that, in addition to female phenotype (especially size and age), reproductive pa rameters are affected by direct selection acting on maternal and offspring fitness, by an individual's survival prospects (cf. residual reproductive value), as well as by population demography (Roff 1992, Stearns 1992). For instance, an increase in reproductive effort, fecundity, and egg size with increasing age of the female are expected when residual reproductive value decreases (Stearns 1992) or when resources available for repro duction increase as a result from diminishing needs to allocate resources to growth (Roff 1992). However, maternal investment can also decrease at older ages as a result of senescence (e.g., Charlesworth 1980, Roff 1992, Giron and Casas 2003). In our data, maternal invest ment increased with age of the females, suggesting a change in resource allocation later in life. The effect of age differed between AO and NO females (Appendix C), however. AO females increased clutch size and TRO with age, suggesting that later in life they (1) invest relatively more in fecundity than in egg size, (2) invest more in reproduction than in growth and/or self maintenance, or (3) increase reproductive effort as a result of decreasing residual reproductive value (cf. Roff 1992, Stearns 1992). In contrast, NO females increased egg size but not clutch size or TRO with age, suggesting that they increase per offspring allocation but not allocation to reproduction later in life.

Maternal investment is often positively correlated with female size, and several explanations have been put forward to explain this pattern (e.g., Parker and Begon 1986, Bernardo 1996, Hendry et al. 2001). First, an increase in fecundity and reproductive effort with increasing female size is expected if larger females have more resources or if they are mechanically less constrained in producing eggs than smaller females (Roff 1992). Accordingly, both AO and NO females increased clutch size and TRO with female size, but further studies are needed to disentangle the exact mechanisms for this observation. The positive relation ship with female size is expected to be stronger for clutch size than for egg size because clutch size should more directly impact female fitness than egg size does, whereas egg size more strongly determines offspring fitness (Einum and Fleming 2000, Hendry et al. 2001). In accordance with this hypothesis, we found a stronger positive relationship between female size and clutch size (than between female size and egg size) in both AO and $\mathrm{NO}$ females. However, in AO females also egg size increased with female size, strengthening the argument that the fitness benefits of investment in egg size are larger in acid than in neutral environments.

We found that the relationship between female age and size and maternal investment generally paralleled those of previous studies and expectations born out of life history theory (Roff 1992, 2003, Stearns 1992). Interestingly, however, the effects of female phenotype differed between AO and NO populations. This suggests that the direct phenotypic effects, the direct fitness benefits, and/or demographic effects (Roff 1992, Stearns 1992) differ between acid and neutral environments. It seems clear that egg size driven fitness benefits should alter the relationships between female phenotype and maternal investment, but to what extent these are influenced by demographic processes, such as differences in age specific mortality or population growth rate, is currently unexplored. This would be a fruitful area of future work for attempts to understand the population level consequences of environmental stress.

In conclusion for this part, we suggest that geographic variation in egg size and clutch size observed here is mediated through variation in both the effects of habitat quality on offspring fitness, and through the effects of female phenotype.

\section{Conclusion}

Taken together, our results support the view that fitness gains from maternal investment, as well as their relationship with female phenotype, differ between 
stressful and benign environments. In particular, our work suggests that environmental acidity (1) lowers maternal investment, (2) favors investment in large eggs at the cost of fecundity, and (3) alters the relationship between female phenotype and maternal investment, as well as strengthens the egg size fecundity trade off. Future work should attempt to establish the genetic basis and the particular selective factors that underlie this geographic variation.

\section{AcKnowledgments}

We thank M. Svensson and P. Jacobsson for help with skeletochronological preparations; K. Varkonyi, E. Nettel bladt, and J. K. Larsson for help in the field; J. Brommer, A. Hendry, J. Hoglund, N. Kolm, G. P. Sætre, J. Jokela, and two anonymous referees for useful comments on earlier versions of this manuscript. The animals were collected and handled with the permissions from Swedish Environmental Protection Agency and the Ethical Committee of Uppsala University. This study was supported by grants from Swedish Agriculture and Forestry Research Council (Juha Merila), The Swedish Natural Science Research Council (Juha Merila), Academy of Finland (Juha Merila), and Oscar and Lili Lamm Foundation (Fredrik Soderman).

\section{Literature Cited}

Andrén, C., L. Henrikson, M. Olsson, and G. Nilson. 1988. Effects of $\mathrm{pH}$ and aluminium on embryonic and early larval stages of Swedish brown frogs Rana arvalis, $R$. temporaria and $R$. dalmatina. Holarctic Ecology 11:127 135.

Armbruster, P., W. E. Bradshaw, K. Ruegg, and C. M. Holzapfel. 2001. Geographic variation and the evolution of reproductive allocation in the pitcher plant mosquito, Wyeomyia smithii. Evolution 55:439 444.

Bernardo, J. 1996. The particular maternal effect of propagule size, especially egg size: patterns, models, quality of evidence, and interpretations. American Zoologist 36:216 236.

Berven, K. A. 1990. Factors affecting population fluctuations in larval and adult stages of the wood frog Rana sylvatica. Ecology 71:1599 1608.

Castanet, J., H. Francillon Vielloit, F. J. Meunieur, and A. de Ricqlès. 1993. Bone and individual ageing. Pages 245283 in B. K. Hall, editor. Bone. Volume 7: Bone growth. CRC Press, Boca Raton, Florida, USA.

Castanet, J., F. J. Meunieur, and A. de Ricqlès. 1977. L'enregistrement de la croissance cyclique par le tissue osseux chez les vertébrés poikilothermes: données comparatives et essai de synthèse. Bulletin Biologique de France et Belgique 16:183 202.

Charlesworth, B. 1980. Evolution in age structured popula tions. Cambridge University Press, Cambridge, UK.

Collier, K. J., O. J. Ball, A. K. Graesser, M. R. Main, and M. J. Winterbourn. 1990. Do organic and anthropogenic acidity have similar effects on aquatic fauna? Oikos 59:33 38 .

Czesak, M. E., and C. W. Fox. 2003. Evolutionary ecology of egg size and number in a seed beetle: genetic trade off differs between environments. Evolution 57:1121 1132.

Dangles, O., B. Malmqvist, and H. Laudon. 2004. Naturally acid freshwater ecosystems are diverse and functional: evidence from boreal streams. Oikos 104:149 155.

Derry, A. M., and S. E. Arnott. 2007. Adaptive reversals in acid tolerance in copepods from lakes recovering from historical stress. Ecological Applications 17:1116 1126.

Einum, S., and I. A. Fleming. 1999. Maternal effects of egg size in brown trout (Salmo trutta): norms of reaction to environmental quality. Proceedings of the Royal Society London B 266:2095 2100.
Einum, S., and I. A. Fleming. 2000. Highly fecund mothers sacrifice offspring survival to maximise fitness. Nature 405: 565567.

Fleming, I. A., and M. R. Gross. 1990. Latitudinal clines: a trade off between egg number and size in Pacific salmon. Ecology 71:1 11 .

Ford, N. B., and R. A. Seigel. 1994. An experimental study of the trade offs between age and size at maturity: effects of energy availability. Functional Ecology 8:91 96.

Girish, S., and S. K. Saidapur. 2000. Interrelationship between food availability, fat, body, and ovarian cycles in the frog, Rana tigrina, with a discussion on the role of fat body in anuran reproduction. Journal of Experimental Zoology 286: 487493.

Giron, D., and J. Casas. 2003. Mothers reduce egg provisioning with age. Ecology Letters 6:273 277.

Glandt, D. 2006. Der Moorfrosch. Einheit und Vielfalt einer Braunfroschart. Laurenti Verlag, Bielefeld, Germany.

Gliwicz, Z. M., and C. Guisande. 1992. Family planning in Daphnia: resistance to starvation in offspring born to mothers grown at different food levels. Oecologia 91:463 467.

Gosner, K. L. 1960. A simplified table for staging anuran embryos and larvae with notes on identification. Copeia 1960:183 190 .

Guhrén, M., C. Bigler, and I. Renberg. 2007. Liming placed in a long term perspective: a paleolimnological study of 12 lakes in the Swedish liming program. Journal of Paleolimnology $37: 247258$.

Hemelaar, A. 1985. An improved method to estimate the number of year rings in phalanges of Bufo bufo (L.) and its application to populations of different latitudes and altitudes. Amphibia Reptilia 6:323 343.

Hendry, A. P., T. Day, and A. B. Cooper. 2001. Optimal size and number of propagules: allowance for discrete stages and effects of maternal size on reproductive output and offspring fitness. American Naturalist 157:387 407.

Hoffmann, A. A., and P. A. Parsons. 1997. Extreme environmental change and evolution. Cambridge University Press, Cambridge, UK.

Hutchings, J. A. 1991. Fitness consequences of variation in egg size and food abundance in brook trout Salvelinus fontinalis. Evolution 45:1162 1168.

Johnston, T. A., and W. C. Leggett. 2002. Maternal and environmental gradients in the egg size of an iteroparous fish. Ecology 83:1777 1791 .

Kaplan, R. H., and P. C. Phillips. 2006. Ecological and developmental context of natural selection: maternal effects and thermally induced plasticity in the frog Bombina orientalis. Evolution 60:142 156.

Kaplan, R. H., and S. N. Salthe. 1979. The allometry of reproduction: an empirical view in salamanders. American Naturalist 113:671 689.

Kisdi, E., G. Meszéna, and L. Pàsztor. 1998. Individual optimization: mechanisms shaping the optimal reaction norm. Evolutionary Ecology 12:211 221.

Komoroski, M. J., R. D. Nagle, and J. D. Congdon. 1998. Relationships of lipids to ovum size in amphibians. Physiological Zoology 71:633 641.

Leuven, R. S. E. W., C. den Hartog, M. M. C. Christiaans, and W. H. C. Heijligers. 1986. Effects of water acidification on the distribution pattern and the reproductive success of amphibians. Experientia 42:495 503.

Littell, R. C., G. A. Milliken, W. W. Stroup, and R. D. Wolfinger. 2006. SAS for mixed models. Second edition. SAS Institute, Cary, North Carolina, USA.

McGinley, M. A., D. H. Temme, and M. A. Geber. 1987. Parental investment in offspring in variable environments: theoretical and empirical considerations. American Natural ist 130:370 398 . 
Merila, J., F. Soderman, R. O'Hara, K. Rasanen, and A. Laurila. 2004. Local adaptation and genetics of acid stress tolerance in the moor frog, Rana arvalis. Conservation Genetics 5:513 527.

Olsen, E. M., and L. A. Vøllestad. 2003. Microgeographical variation in brown trout reproductive traits: possible effects of biotic interactions. Oikos 100:483 492.

Olsson, M., and R. Shine. 1997. The limits to reproductive output: offspring size versus number in the sand lizard (Lacerta agilis). American Naturalist 149:179 188.

Parker, G. A., and M. Begon. 1986. Optimal egg size and clutch size: effects of environment and maternal phenotype. American Naturalist 128:573 592.

Pierce, B. A. 1985. Acid tolerance in amphibians. BioScience 35 : 239243.

Poulin, R. 1995. Clutch size and egg size in free living and parasitic copepods: a comparative analysis. Evolution 49: 325336.

Rasanen, K., and D. M. Green. In press. Acidification and its effects on amphibian populations. In $\mathrm{H}$. Heatwole, editor. Amphibian biology. Volume 8. Conservation and ecology. Surrey Beatty and Sons, Chipping Norton, Australia.

Rasanen, K., A. Laurila, and J. Merila. 2003a. Geographic variation in acid stress tolerance in the moor frog, Rana arvalis. I. Local adaptation. Evolution 57:352 362.

Rasanen, K., A. Laurila, and J. Merila. 2003b. Geographic variation in acid stress tolerance in the moor frog, Rana arvalis. II. Adaptive maternal effects. Evolution 57:363 371.

Rasanen, K., A. Laurila, and J. Merila. 2005. Maternal investment in egg size: environment and population specific effects on offspring performance. Oecologia 142:546 553.

Renberg, I., T. Korsman, and N. J. Andersson. 1993. A temporal perspective of lake acidification in Sweden. Ambio 22:264 271

Reznick, D. N., and C. K. Ghalambor. 2001. The population ecology of contemporary adaptations: what empirical studies reveal about the conditions that promote adaptive evolution. Genetica 112 113:183 198.

Reznick, D., L. Nunney, and A. Tessier. 2000. Big houses, big cars, superfleas, and the cost of reproduction. Trends in Ecology and Evolution 15:421 425.
Roff, D. A. 1992. The evolution of life histories. Chapman and Hall, New York, New York, USA.

Roff, D. A. 2003. Life history evolution. Sinauer Associates, Sunderland, Massachusetts, USA.

Rusek, J., and V. G. Marshall. 2000. Impacts of airborne pollutants on soil fauna. Annual Reviews in Ecology and Systematics 31:395 423 .

Scott, D. E. 1994. The effect of larval density on adult demographic traits in Ambystoma opacum. Ecology 75:1383 1396.

Sinervo, B. 1999. Mechanistic analysis of natural selection and a refinement of Lack's and Williams's principles. American Naturalist 154:S26 S42.

Sinervo, B., P. Doughty, R. B. Huey, and K. Zamudio. 1992. Allometric engineering: a causal analysis of natural selection on offspring size. Science 258:1927 1930.

Sinervo, B., and P. Licht. 1991. Proximate constraints on the evolution of egg size, number and clutch mass in lizards. Science 252:1300 1302.

Smith, C. C., and S. D. Fretwell. 1974. The optimal balance between size and number of offspring. American Naturalist 108:499 506.

Smith, D. C. 1987. Adult recruitment in chorus frogs: effects of size and date at metamorphosis. Ecology 68:344 350 .

Soderman, F. 2006. Comparative population ecology in moor frogs with particular reference to acidity. Dissertation. Uppsala University, Uppsala, Sweden.

Soderman, F., S. van Dongen, S. Pakkasmaa, and J. Merila. 2007. Environmental stress increases skeletal fluctuating asymmetry in the moor frog (Rana arvalis). Oecologia 151: 593604.

Stearns, S. C. 1992. The evolution of life histories. Oxford University Press, Oxford, UK.

Tuomi, J. 1990. On clutch size and parental survival. Oikos 58: 387389.

Trippel, E. A., and H. H. Harvey. 1987. Reproductive responses of five white sucker (Catostomus commersoni) populations in relation to lake acidity. Canadian Journal of Fisheries and Aquatic Sciences 44:1018 1023.

Van Noordwijk, A. J., and G. De Jong. 1986. Acquisition and allocation of resources: their influence on variation in life history tactics. American Naturalist 128:137 142.

\section{APPENDIX A}

Descriptive information about study populations (Ecological Archives E089 143 A1).

\section{APPENDIX B}

Additional statistical analyses on the relationship between phenotype and maternal investment (Ecological Archives E089 143 A2).

\section{APPENDIX C} A3).

Additional analyses of covariance on the effects of female phenotype on egg size and clutch size (Ecological Archives E089 143 